\title{
MORPHOLOGICAL AND OPTOSTRUCTURAL STUDIES ON HYDRAZINE HYDRATE ASSISTED $\mathrm{Zr}\left(\mathrm{SeO}_{3}\right)_{2}$ NANOPARTICLES
}

\author{
J. HENRY', K. MOHANRAJ ${ }^{1, *}$, S. KANNAN ${ }^{1}$, S. BARATHAN ${ }^{2}$ AND G. SIVAKUMAR ${ }^{3}$ \\ ${ }^{I}$ Department of Physics, Manonmaniam Sundaranar University, Tirunelveli-627 012, Tamil Nadu, India. \\ ${ }^{2}$ Department of Physics, Annamalai University, Annamalai Nagar-608 002, Tamil Nadu, India. \\ ${ }^{3}$ CISL, Department of Physics, Annamalai University, Annamalai Nagar-608 002, Tamil Nadu, India.
}

(Received: November 15, 2012 - Accepted: April 3, 2013)

\begin{abstract}
Zirconium diselenite $\left(\mathrm{Zr}\left(\mathrm{SeO}_{3}\right)_{2}\right)$ nanoparticles have been prepared by precipitation method using $\mathrm{ZrO}\left(\mathrm{NO}_{3}\right)_{2} \times \mathrm{xH}_{2} \mathrm{O}$ and $\mathrm{SeO}$ with $\mathrm{Hydrazine}$ hydrate and vary the temperature. The obtained samples were characterised by using XRD, FTIR, FESEM and optical analysis. The XRD study shows the orthorhombic crystalline structure and particle sizes is found to be $78.06,42.13$ and $27.17 \mathrm{~nm}$ for $0.25: 1,0.5: 1$ and $0.75: 1 \mathrm{M}$ respectively. FTIR results are confirmed the $\mathrm{Zr}\left(\mathrm{SeO}_{3}\right)_{2}$ at 885 $\mathrm{cm}^{-1}, 739 \mathrm{~cm}^{-1}$ and $491 \mathrm{~cm}^{-1}$. FESEM images provide different shapes such as cubic and hexagonal of $\mathrm{Zr}\left(\mathrm{SeO}_{3}\right)_{2}$. Maximum absorption is found around $387 \mathrm{~nm}$ and the percentage of optical absorption is increased in the entire visible region when the molar concentration of zirconium decreases. The average band gap energy of the samples are found to be $3.95 \pm 2 \mathrm{eV}$. It is observed that the optical absorption is higher in the hydrazine hydrate assisted samples.
\end{abstract}

Key words: Zirconium diselenite, Hydrazine hydrate, XRD, FTIR, FESEM

\section{INTRODUCTION}

Ion-exchange processes were studied systematically in the middle of the last century. The first commercially available ion-exchangers were amorphous aluminosilicate gels. These exchangers were known to be unstable towards acidic solutions. This variability in their behavior led chemists to seek alternatives. This search eventually led to the synthesis of the first organic ion-exchange resins which dominated the field until the post world war II era. The advent of nuclear technology initiated a search for inorganic ion exchange materials that would remain stable above $150^{\circ} \mathrm{C}$ and in high radiation fields. ${ }^{1,2}$

The uses of inorganic ion-exchangers have been explored only in the beginning of the last two decades. Since then the analytical applications of synthetic inorganic ion-exchangers have attracted great attention. The important features of these materials are: the differential selectivity, the ease of preparation extra stability under ionizing radiations and at high temperature. It is inspired the authors to prepare the inorganic ion-exchange. To know our knowledge, there is found few literatures in the globe for preparation of zirconium diselenite using zirconium oxide as starting material. ${ }^{1,2}$ However, the authors are not reported the optical and structural properties of zirconium diselenite. Hence, objective of the study is to prepare the zirconium diselenite nanoparticles using zirconyl nitrate as a starting material and study the structural and optical properties. Also, interested to carry out the influence of hydrazine hydrate and temperature.

\section{EXPERIMENTAL}

To synthesize zirconium diselenite nanoparticles, $\mathrm{AR} \mathrm{Grade} \mathrm{of} \mathrm{ZrO}\left(\mathrm{NO}_{3}\right)_{2}$. $\mathrm{xH}_{2} \mathrm{O}$ and $\mathrm{SeO}_{2}$ were taken in three different molar ratio 0.25:1, 0.5:1 and $0.75: 1$, completely dissolved in distilled water. Then the solutions were mixed together and again stirred vigorously about 5 hour in room temperature. A white precipitate was obtained which was thoroughly washed using ethanol and water, then dried in a oven at $60^{\circ} \mathrm{C}$ for two hours. The powder samples were grained by using agate mortor and pestle. The same procedure was used to prepare the $0.5: 1 \mathrm{M}$ sample at $60{ }^{\circ} \mathrm{C}$ and hydrazine hydrate assisted zirconium diselenite nanoparticles at room temperature.

Crystalline phases of the $\mathrm{Zr}\left(\mathrm{SeO}_{3}\right)_{2}$ nanoparticles were investigated by PANalytical X'PERT PRO diffractometer with $\mathrm{Cu} \mathrm{K \alpha}$ monochromatic radiation source $(\lambda=1.5406 \AA)$ in the range of $2 \theta=10^{\circ}-80^{\circ}$. Molecular vibrations of the $\mathrm{Zr}\left(\mathrm{SeO}_{3}\right)_{2}$ nanoparticles were carried out using Perkin Elmer FTIR spectrometer (Model RX-I) with the wavelength range of $2000-400$ $\mathrm{cm}^{-1}$. FESEM images were taken by FESEM Curl-Zeiss instrument. Optical absorbance characterization of the particles were recorded using JASCO UVIDEC - 650 UV-VIS Spectrophotometer in the range 300 to $800 \mathrm{~nm}$.

\section{RESULTS AND DISCUSSION}

Figure 1(a-c) shows the XRD patterns of $\mathrm{Zr}\left(\mathrm{SeO}_{3}\right)_{2}$ nanoparticles prepared in different molar concentration $(0.25: 1,0.5: 1,0.75: 1)$ of $\mathrm{ZrO}\left(\mathrm{NO}_{3}\right)_{2} \cdot \mathrm{xH}_{2} \mathrm{O}$ and
$\mathrm{SeO}_{2}$ at room temperature. From the XRD pattern (Fig. 1 (a)), strong intensity peaks observed at $2 \theta=21.73^{\circ}, 24.95^{\circ}, 27.55^{\circ}$ and $28.36^{\circ}$ which are owing to the diffractions of planes (2 $\left.\begin{array}{lll}2 & 1\end{array}\right),\left(\begin{array}{lll}2 & 1 & 0\end{array}\right),\left(\begin{array}{lll}2 & 1 & 2\end{array}\right),\left(\begin{array}{lll}0 & 2 & 1\end{array}\right)$ respectively and some medium intensity peaks are observed and reported in Table.1.

The XRD results confirmed orthorhombic crystal structure (JCPDS No.50-0336) and lattice parameters of the particle are found to be $\mathrm{a}=8.5549 \AA$, $\mathrm{b}=6.479 \AA$ and $\mathrm{c}=15.2317 \AA$. In the same pattern, an additional peak present at $29.1^{\circ}$ which perhaps due to the reflections of the plane $\left(\begin{array}{lll}1 & 0 & 0\end{array}\right)$. It can be assigned to hexagonal structure of $\mathrm{Zr}_{3} \mathrm{Se}_{2}$ impurity (JCPDS. No.15-0249). In Figure $1(\mathrm{c})$ the characteristics peak appears poor crystalline nature at $0.75: 1 \mathrm{M}$.

Table 1. XRD result of $\mathrm{Zr}\left(\mathrm{SeO}_{3}\right)_{2}$

\begin{tabular}{|c|c|c|c|}
\hline S.No & $\begin{array}{l}\text { Standard } \\
2 \theta \text { value }\end{array}$ & $\begin{array}{l}\text { Observed } \\
2 \theta \text { value }\end{array}$ & (h k l) \\
\hline 1 & 17.14 & 17.11 & $\left(\begin{array}{lll}1 & 1 & 0\end{array}\right)$ \\
\hline 2 & 20.79 & 20.73 & $\left(\begin{array}{lll}1 & 1 & 2\end{array}\right)$ \\
\hline 3 & 21.82 & 21.78 & $\left(\begin{array}{lll}2 & 0 & 1\end{array}\right)$ \\
\hline 4 & 24.99 & 24.95 & $\left(\begin{array}{lll}2 & 1 & 0\end{array}\right)$ \\
\hline 5 & 27.58 & 27.55 & $\left(\begin{array}{lll}2 & 1 & 2\end{array}\right)$ \\
\hline 6 & 28.44 & 28.36 & $\left(\begin{array}{lll}0 & 2 & 1\end{array}\right)$ \\
\hline 7 & 29.31 & 29.35 & $\left(\begin{array}{lll}0 & 0 & 5\end{array}\right)$ \\
\hline 8 & 34.31 & 34.33 & $\left(\begin{array}{lll}3 & 1 & 0\end{array}\right)$ \\
\hline 9 & 34.65 & 34.66 & $\left(\begin{array}{lll}2 & 2 & 0\end{array}\right)$ \\
\hline 10 & 37.03 & 37.08 & $\left(\begin{array}{lll}1 & 0 & 6\end{array}\right)$ \\
\hline 11 & 37.72 & 37.69 & $\left(\begin{array}{lll}1 & 2 & 4\end{array}\right)$ \\
\hline 12 & 38.90 & 38.93 & $\left(\begin{array}{lll}2 & 1 & 5\end{array}\right)$ \\
\hline 13 & 40.38 & 40.38 & $\left(\begin{array}{lll}0 & 2 & 5\end{array}\right)$ \\
\hline 14 & 44.44 & 44.39 & $\left(\begin{array}{lll}4 & 1 & 0\end{array}\right)$ \\
\hline 15 & 46.68 & 46.63 & $\left(\begin{array}{lll}2 & 0 & 7\end{array}\right)$ \\
\hline 16 & 47.53 & 47.52 & $\left(\begin{array}{lll}2 & 3 & 1\end{array}\right)$ \\
\hline 17 & 51.08 & 51.06 & $\left(\begin{array}{lll}4 & 2 & 0\end{array}\right)$ \\
\hline 18 & 55.89 & 55.88 & $\left(\begin{array}{lll}0 & 2 & 8\end{array}\right)$ \\
\hline 19 & 58.63 & 58.61 & $\left(\begin{array}{lll}3 & 3 & 4\end{array}\right)$ \\
\hline
\end{tabular}




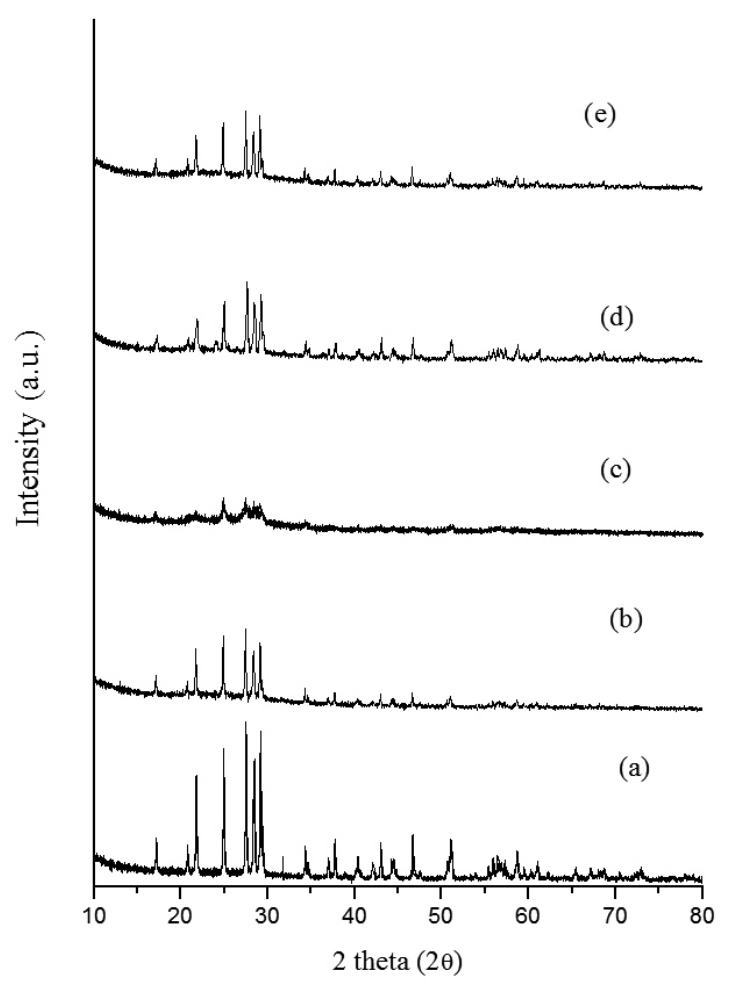

Fig. 1. XRD patterns of $\mathrm{Zr}\left(\mathrm{SeO}_{3}\right)_{2}$ nanoparticles in different molar ratios (a) $0.25: 1$, (b) $0.5: 1$, (c) $0.75: 1$, (d) $0.5: 1$ at $60{ }^{\circ} \mathrm{C}$, (e) $0.5: 1$ with Hydrazine hydrate

Figure 1 ( $\mathrm{d} \&$ e) show the XRD patterns of Zirconium diselenite prepared at $60{ }^{\circ} \mathrm{C}$ and hydrazine hydrate assisted sample respectively. The results seem like to be similar as that of intensity in Fig. 1(a). However, the characteristic peaks get reduced in the hydrazine hydrate assisted samples. It may be due to the hydrazine hydrate can modify the structure of $\mathrm{Zr}\left(\mathrm{SeO}_{3}\right)_{2}$ sample. Similar results also shown in the XRD pattern of Zirconium diselenite prepared at 60 ${ }^{\circ} \mathrm{C}$ (Figure 1(d)).

$\mathrm{Zr}\left(\mathrm{SeO}_{3}\right)_{2}$ nanoparticles have been formed according to the following over all reactions. ${ }^{3,4}$

$$
\begin{aligned}
& \mathrm{ZrO}\left(\mathrm{NO}_{3}\right)_{2} \cdot \mathrm{xH}_{2} \mathrm{O} \longrightarrow \mathrm{ZrO}^{2+}+2\left(\mathrm{NO}_{3}\right)^{-}+\mathrm{xH}_{2} \mathrm{O} \\
& \mathrm{H}_{2} \mathrm{SeO}_{3} \longrightarrow 2 \mathrm{H}^{+}+\left(\mathrm{SeO}_{3}\right)^{2-} \\
& \mathrm{ZrO}^{2+}+\mathrm{H}_{2} \mathrm{SeO}_{3} \longrightarrow \mathrm{ZrOSeO}_{3}+2 \mathrm{H}^{+} \\
& \mathrm{ZrOSeO}_{3}+\mathrm{H}_{2} \mathrm{SeO}_{3} \longrightarrow \mathrm{Zr}\left(\mathrm{SeO}_{3}\right)_{2}+\mathrm{H}_{2} \mathrm{O}
\end{aligned}
$$

The peak broadening at lower angle is more meaningful for the calculation of particle size. The average crystallite size of all the zirconium diselenite samples was calculated using the Scherrer's formula. $D=k \lambda / \beta \cos \theta$, where $D$ is the crystalline size, $\mathrm{k}$ is the Scherrer's constant $(\mathrm{k}=0.9), \lambda$ the wavelength of the $\mathrm{X}$-ray, $\beta$ the full-peak width at half of the maximum intensity after correction for the instrument-broadening contributions and $\theta$ the peak position

Dislocations are the imperfections in a crystal and associated with the mis-registry of the lattice in one part of the crystal with respect to another part. Unlike vacancies and interistitial atoms, dislocations are not equilibrium imperfections. In fact, the growth mechanism involving dislocations is a matter of importance. The dislocation densities of thin films are given by the Williamson and smallman's relation. $\delta=n / \mathrm{D}^{2}$, where $\delta$ is dislocation density, $\mathrm{n}$ is a factor, which equals unity, giving minimum dislocation density and $\mathrm{D}$ is the grain size. ${ }^{6}$ Table 2 gives the grain size and dislocation density of all prepared samples.

\begin{tabular}{|c|c|c|c|c|c|}
\hline $\begin{array}{l}\text { S. } \\
\text { No }\end{array}$ & $\begin{array}{c}\text { Molar } \\
\text { ratio }\end{array}$ & $\begin{array}{l}\text { Hydrazine } \\
\text { hydrate }\end{array}$ & condition & $\begin{array}{c}\text { Grain } \\
\text { size }(n m)\end{array}$ & $\begin{array}{c}\text { Dislocation } \\
\text { density }\left(10^{14}\right. \\
\left.\operatorname{lin} / \mathrm{m}^{2}\right)\end{array}$ \\
\hline 1 & $0.25: 1$ & No & \multirow{4}{*}{$\begin{array}{c}\text { Room } \\
\text { Temperature }\end{array}$} & 78.06 & 1.6 \\
\hline 2 & $0.5: 1$ & No & & 42.13 & 5.6 \\
\hline 3 & $0.75: 1$ & No & & 27.17 & 13 \\
\hline 4 & $0.5: 1$ & Yes & & 57.75 & 3 \\
\hline 5 & $0.5: 1$ & No & $\begin{array}{c}\text { Temperature } \\
\text { at } 60^{\circ} \mathrm{C}\end{array}$ & 48.15 & 4.13 \\
\hline
\end{tabular}

Table 2. Grain size of $\mathrm{Zr}\left(\mathrm{SeO}_{3}\right)_{2}$ nanoparticles at different conditions.

Figure 2 show the FTIR spectra of $0.5: 1 \mathrm{M} \mathrm{Zr}\left(\mathrm{SeO}_{3}\right)_{2}$ (a) at room temperature, (b) at $60{ }^{\circ} \mathrm{C}$ and (c) using hydrazine hydrate at room temperature. In Fig. 2 (a), a medium intensity band observed at $1650 \mathrm{~cm}^{-1}$ which is due to hydroxyl groups of water molecules. ${ }^{6}$ A strong band is observed around 739 $\mathrm{cm}^{-1}$ which may be due to either the $\mathrm{Zr}-\mathrm{O}_{2}-\mathrm{Zr}$ asymmetric stretching or the stretches of Se-O bonds in the $\mathrm{SeO}_{3}{ }^{2-}$ anions. ${ }^{2}, 8$ The authors have been assigned the band (at $739 \mathrm{~cm}^{-1}$ ) in two different kinds of molecular vibrations. H. Ranjan Sahu et al.,(2000) ${ }^{7}$ have assigned the $\mathrm{Zr}-\mathrm{O}_{2}-\mathrm{Zr}$ asymmetric stretching for the band at $739 \mathrm{~cm}^{-1}$ and Jie Ling et al.,(2007) ${ }^{8}$ have assigned the Se-O band at 739 $\mathrm{cm}^{-1}$. In the spectrum, a strong band at $491 \mathrm{~cm}^{-1}$ is due to the $\mathrm{Zr}-\mathrm{O}$ stretching mode ${ }^{7}$ which is confirmed the $\mathrm{Zr}$ ions. Also, a band shown at $885 \mathrm{~cm}^{-1}$ which is due to stretching vibrations of Se-O bonds ${ }^{8}$ and a hump is noticed at $1100 \mathrm{~cm}^{-1}$ which is owing to the Zirconia 7 . In Fig. 2 (b \& c) the characteristic bands are (at $1100,885,739$ and $491 \mathrm{~cm}^{-1}$ ) as similar to that of Fig. 2 (a). However, the band at $739 \mathrm{~cm}^{-1}$ seems to be broad in Fig. 2 (b) which may due to external thermal treatment on the sample (at $60{ }^{\circ} \mathrm{C}$ ). The observed FTIR results are supported to the XRD analysis.

Figure 3 (a-d) shows the UV-Visible absorption spectra of zirconium diselenite prepared in different molarities and hydrazine hydrate at room temperature. In all the UV-VIS spectrum, a maximum absorption peak found around $385 \mathrm{~nm}$ which is due to $\mathrm{Zr}\left(\mathrm{SeO}_{3}\right)_{2}$ and starts decreases around $400 \mathrm{~nm}$ and became constant upto the entire region. However all the samples show a good optical absorption in the range between 1000 and $400 \mathrm{~nm}$. In $0.75 \mathrm{M}$ (Fig. 3 (a)), there is a shift in maximum absorption and its absorption starts decreasing from $500 \mathrm{~nm}$. It can be regarded as an excitonic peak for $\mathrm{Zr}\left(\mathrm{SeO}_{3}\right)_{2}$ nanocrystals and proves the existence of $\mathrm{Zr}\left(\mathrm{SeO}_{3}\right)_{2}$ nanoparticle. The results are in agreement with the earlier reports for $\left(\mathrm{SeO}_{3}\right)_{2}$ composite materials. ${ }^{9}$

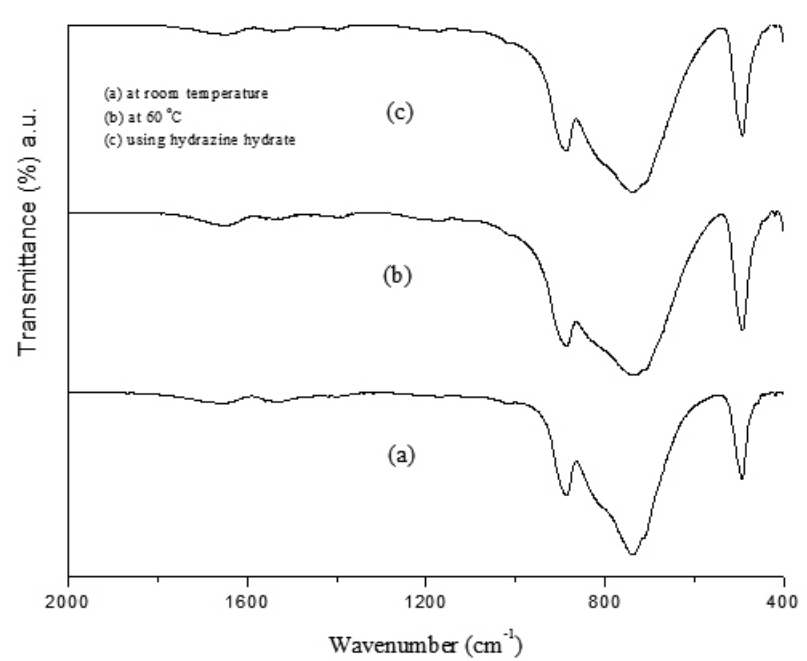

Fig. 2. FTIR spectra of $0.5: 1 \mathrm{M} \mathrm{Zr}\left(\mathrm{SeO}_{3}\right)_{2}$ nanoparticles 


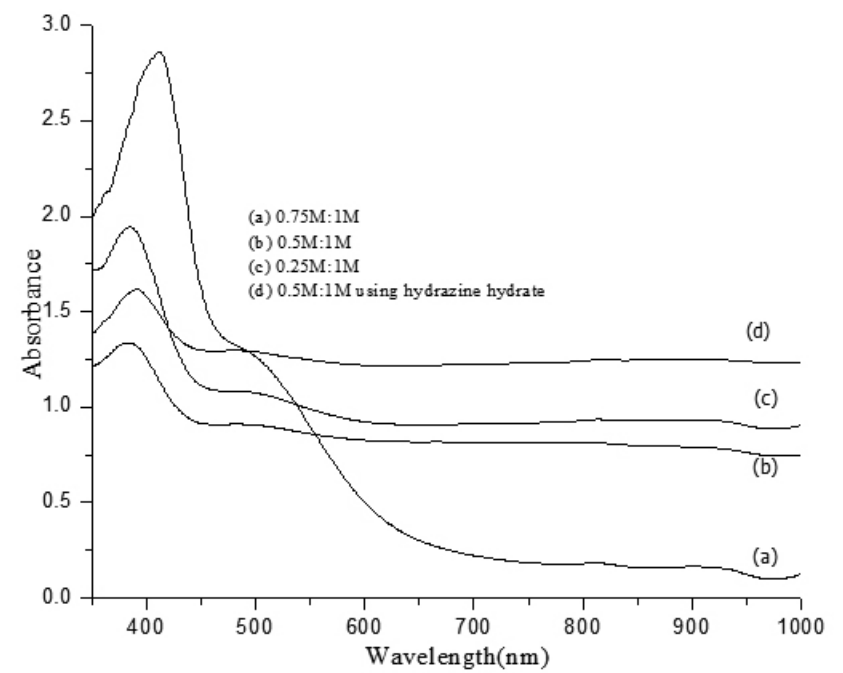

Fig. 3. UV-VIS absorption spectra of $\mathrm{Zr}\left(\mathrm{SeO}_{3}\right)_{2}$

To determine the optical band gap, the following dependence of $\alpha$ on photon energy was used $(\alpha \mathrm{h} v) \alpha\left(\mathrm{h} v-\mathrm{E}_{\mathrm{g}}\right)^{\mathrm{n}}$ where $\mathrm{E}_{\mathrm{g}}$ is band gap; $\alpha$ is absorption coefficient; $\mathrm{n}$ is an index that can assume values of $(1 / 2,2)$, depending on the nature of electronic transitions. For the direct allowed transitions, $n$ has a value of $1 / 2$ while for indirect allowed transitions $n=2$.

The optical band gaps for direct transitions are evaluated from the plot of $(\alpha h v)^{2} \mathrm{Vs}(\mathrm{h} v)$ (Fig. 4). The plot for direct transitions shows a straight line and yields a value in the range from 3.93 to $3.97 \mathrm{eV}$.

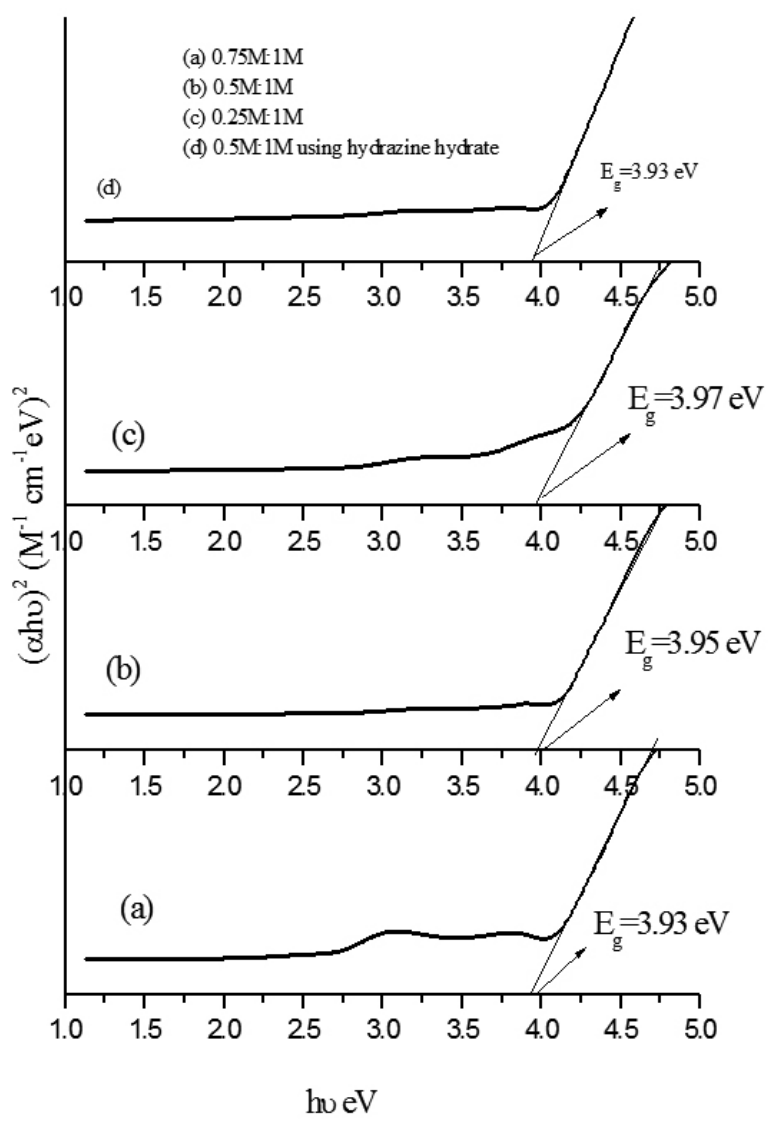

Fig. 4. The plot of $(\alpha h v)^{2}$ Vs $(h v)$.
Figure $5(\mathrm{a} \& \mathrm{~b})$ shows the FESEM images of $0.25 \mathrm{M}$ : $1 \mathrm{M}$ zirconium diselenite nanoparticle at room temperature. In Fig.5 (a), the $\mathrm{Zr}\left(\mathrm{SeO}_{3}\right)_{2}$ particles found to be different shapes like cubes and hexagons in shape and are dispersed on the surface which seems, like more compact. It is clearly seen in the higher magnification image (Fig.5 (b)). The average particle size is found to be $200 \mathrm{~nm}$. The Fig. 5 (c \& d) shows the FESEM image of $0.5 \mathrm{M}$ : $1 \mathrm{M}$ zirconium diselenite particles prepared using hydrazine hydrate. The average size of the particle are found to be $220 \mathrm{~nm}$ which is bigger than $\mathrm{Zr}\left(\mathrm{SeO}_{3}\right)_{2}$ prepared at room temperature (Fig. $5(\mathrm{a}-\mathrm{b})$ ). It may be due to the influence of Hydrazine hydrate in the mixture and a large amount of cubic particles are dispersed.
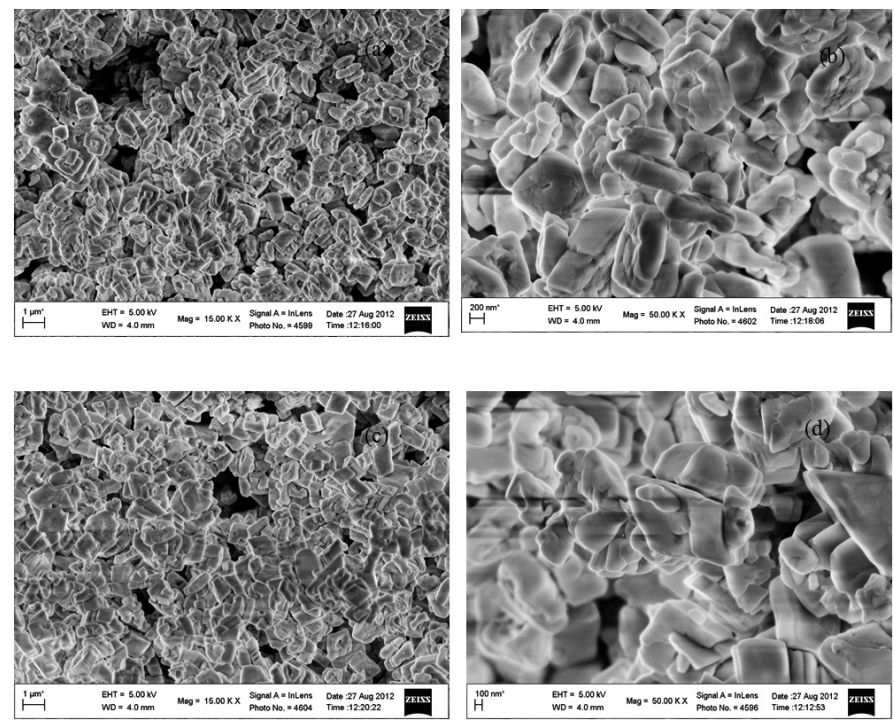

Fig. 5. FESEM image of the Zirconium diselenite prepared in $0.5 \mathrm{M}$ : $1 \mathrm{M}$ at room temperature (a) low magnification, (b) high magnification, (c) low magnification in hydrazine hydrate, (d) high magnification in hydrazine hydrate.

\section{CONCLUSION}

In this paper, zirconium diselenite nanoparticles $\left(\mathrm{Zr}\left(\mathrm{SeO}_{3}\right)_{2}\right)$ have been synthesised in three different condition by precipitation method with three different molar concentration.

The XRD results are confirmed the orthorhombic crystal structure of zirconium diselenide and the FTIR results are also confirmed the zirconium diselenite at $885 \mathrm{~cm}^{-1}, 739 \mathrm{~cm}^{-1}$ and $491 \mathrm{~cm}^{-1}$. The FESEM images are visually shown the cubic and hexagonal shape of the $\mathrm{Zr}\left(\mathrm{SeO}_{3}\right)_{2}$ particles. Large size particles are seen in the hydrazine hydrate assisted samples. From the optical study, maximum absorption is found around $387 \mathrm{~nm}$ and the percentage of optical absorption is increased in the visible region when the molar concentration of zirconium decreases. The optical absorption is higher in the hydrazine hydrate assisted samples. The average band gap values of the samples are found to be $3.95 \pm 2 \mathrm{eV}$. From the above experimental results, it is concluded that the hydrazine hydrate didn't reduced the band gap value. It is confirmed that these two different conditions have modify the structure of the $\mathrm{Zr}\left(\mathrm{SeO}_{3}\right)_{2}$ particles and Band gap energy values.

\section{ACKNOWLEDGEMENT}

The authors are thankful to the UGC-SAP, New Delhi for provided the financial support to the department of Physics, Manonmaniam Sundaranar University, Tirunelveli, Tamil Nadu, India and the Prof \& Head, Department of Physics, Annamalai University for provided the Analytical instrumentation facilities. Also the authors are thankful to authorities of the Manonmaniam Sundaranar University, Tirunelveli for provided the seed money project to carry out the work.

\section{REFERENCES}

1. N. Retta, T. Sisly, Bull. Chem. Soc. Ethiop. 8, 1, (1994).

2. V.P. Nesterenko, J. Thermal analysis and calorimetry. 80, 575, (2005) 
3. A.M. Sargar, N.S .patil, S.R. Mane, S.N. Gawale, P.N. Bhosale, Int. J. Electrochem. Sci. 4, 887, (2009)

4. S.G. Simpson, W.C. Schums, Cambridge, Massachusetts, 921, (1934)

5. P. Manivasakan, V. Rajendran, P.R. Rauta, B.B. Sahu, B.K. Panda, J. Am. Ceram. Soc. 94, 1410, (2011)

6. Rahul, S.R. Vishwakarma, R.N. Tirupathi, A.K. Verma, The African review of physics $6,103,(2011)$
7. C.Y. Tai, B. Hsiao, H. Chiu, Colloids and surfaces A: Physicochem.E ng. Aspects, 237, 105, (2004)

8. H.R. Sahu, G.R. Rao, Bull. Mater. Sci., 23, 349, (2000)

9. J. Ling, T.E. Albrecht-Schmitt, J. Solid state chem., 180, 1601, (2007)

10. S. Zhang, C. Hu, P. Li, H. Jiang, J. Mao, Dalton Trans.,41, 9532, 